https://helda.helsinki.fi

\title{
High bone mass due to novel LRP5 and AMER1 mutations
}

\section{Costantini, Alice}

2017-12

Costantini , A , Kekalainen , P , Makitie , R E \& Makitie , O 2017 , ' High bone mass due to novel LRP5 and AMER1 mutations ' , European Journal of Medical Genetics , vol. 60 , no. 12 , pp. 675-679 . https://doi.org/10.1016/j.ejmg.2017.09.001

http://hdl.handle.net/10138/298168

https://doi.org/10.1016/j.ejmg.2017.09.001

publishedVersion

Downloaded from Helda, University of Helsinki institutional repository.

This is an electronic reprint of the original article.

This reprint may differ from the original in pagination and typographic detail.

Please cite the original version. 


\title{
High bone mass due to novel LRP5 and AMER1 mutations
}

\author{
Alice Costantini ${ }^{\text {a, * }}$, Päivi Kekäläinen ${ }^{\text {b }}$, Riikka E. Mäkitie ${ }^{c}$, Outi Mäkitie ${ }^{\text {a, c, d, e }}$ \\ a Department of Molecular Medicine and Surgery, Center for Molecular Medicine, Karolinska Institutet, Stockholm, Sweden \\ b Department of Internal Medicine, Hospital District of North Karelia, Joensuu, Finland \\ ${ }^{\mathrm{c}}$ Folkhälsan Institute of Genetics, University of Helsinki, Helsinki, Finland \\ ${ }^{\mathrm{d}}$ Children's Hospital, University of Helsinki and Helsinki University Hospital, Helsinki, Finland \\ e Department of Clinical Genetics, Karolinska University Hospital, Stockholm, Sweden
}

\section{A R T I C L E I N F O}

\section{Article history:}

Received 16 June 2017

Received in revised form 8 August 2017

Accepted 7 September 2017

Available online 8 September 2017

\section{Keywords:}

High bone mass

Osteopathia striata

WNT signaling

LRP5

AMER1

\begin{abstract}
A B S T R A C T
WNT signaling is a key regulator of bone metabolism and its increased or decreased activity leads to skeletal disorders. Here we describe two patients with high bone mass (HBM) caused by novel mutations in two different WNT pathway components.

The first patient is a 53-year-old male with HBM. He was diagnosed at adult age based on significantly increased bone mineral density (BMD). He has undergone several surgeries due to excessive bone in ear canals, bilateral jaw exostoses and mandibular tori. Radiographs show severe cortical thickening of cranial and long bones. Sanger sequencing identified a novel heterozygous mutation c.592A $>$ T (p.N198Y) in LRP5 (Low-density lipoprotein receptor-related protein 5). The second patient, an adolescent female, was diagnosed with skeletal dysplasia in early childhood. She had macrocephaly (head circumference +6.0 SD), facial dysmorphism, delayed motor development, laryngomalasia and epilepsy. Radiographic findings were consistent with osteopathia striata with cranial sclerosis. A novel heterozygous frameshift mutation c.655del (p.E219Rfs*63) in AMER1 (APC Membrane Recruiting Protein 1) was identified. Although both mutations are predicted to lead to increased WNT signaling with a consequent increase in bone formation, the resulting phenotypes are different; cranial sclerosis versus macrocephaly, long bone cortical thickening versus vertical striations and discordant neurological development. This report underscores the diversity of genotypes and phenotypes of HBM and facilitates their differential diagnosis.
\end{abstract}

๑) 2017 Elsevier Masson SAS. All rights reserved.

\section{Background}

Canonical WNT/ $\beta$-catenin pathway plays an essential role in bone health. It affects both osteoblast and osteoclast differentiation and function and partakes in bone homeostasis from prenatal skeletal development to adult age. Dysregulated WNT signaling is a known cause of various forms of inherited bone mass disorders. For example, early-onset osteoporosis can be caused by loss-offunction mutations in the ligand WNT1 (Wnt Family Member 1) (Laine et al., 2013; Makitie et al., 2016) or in the co-receptor protein LDL Receptor Related Protein 5 (LRP5) (Gong et al., 2001; Laine et al., 2011; Saarinen et al., 2010). On the other hand, increased WNT

\footnotetext{
* Corresponding author. Department of Molecular Medicine and Surgery, Center for Molecular Medicine (CMM) L8:02, Karolinska University Hospital Solna, 171 76, Stockholm, Sweden.

E-mail address: alice.costantini@ki.se (A. Costantini).
}

signaling due to, for instance, gain-of-function mutations in LRP5, leads to increased bone formation with excessive cortical thickening, dense long bones and craniofacial abnormalities (Balemans et al., 2007). Two high bone mass (HBM) disorders, van Buchem disease (Loots et al., 2005) and sclerosteosis (Balemans et al., 2001), are caused by loss-of-function mutations in SOST, encoding the WNT antagonist sclerostin. Furthermore, mutations in the gene encoding the WNT inhibitor APC membrane recruitment 1 (AMER1) cause a specific form of HBM called osteopathia striata with cranial sclerosis (OSCS) (Holman et al., 2011; Jenkins et al., 2009).

Here we describe two patients affected by HBM due to novel mutations in two different WNT pathway-related genes. These heterozygous mutations in LRP5 and AMER1 are predicted to lead to increased WNT signaling. The resulting conditions both associate with HBM but differ in several clinical and radiographic features, as illustrated by the two cases. 


\section{Patients data/material}

Patients were identified during the course of an ongoing research program on skeletal dysplasias in Finland. The study was approved by the Institutional Ethics Board at Children's Hospital, Helsinki University Hospital, Finland. Hospital data were reviewed retrospectively and genetic studies performed for diagnostic purposes. Peripheral blood genomic DNA was extracted using standard methods.

\section{Methods}

For Patient 1 PCR was performed using Taq DNA polymerase (ThermoFisher Scientific) and primers were designed to amplify exons 2-4 of the LRP5 gene (reference sequence: NM_002335.3). Primer sequences are available from authors upon request. Sanger sequencing was performed according to standard procedures. For Patient 2, genomic DNA was evaluated for a panel of genes associated with osteopetrosis at Bristol RGC, UK Genetic Testing Network. The panel included 21 genes (ANKH, AMER1, CA2, CLCN7, CTSK, FAM20C, FERMT3, IKBKG, LEMD3, LRP5, OSTM1, PLEKHM1, PTH1R, RASGRP2, SNX10, SOST, TCIRG1, TGFB1, TNFRSF11A, TNFSF11 and TYROBP).

\section{Results}

\subsection{Patient I}

This 53-year-old male had a history of ulcerative colitis, for which he was treated with oral mesalazine and methylprednisolone periodically. To exclude secondary osteoporosis he underwent dual-energy X-ray absorptiometry (DXA). Unexpectedly, he had markedly increased bone mineral density (BMD) with T-scores for femoral neck +7.2 and for lumbar spine +10.1 . Based on subsequent clinical and radiographic evaluations he was diagnosed with HBM. Prior to diagnosis he had undergone several operations: two ear canal operations due to excessive bone formation, and surgical removal of bilateral jaw exostoses and mandibular tori. He had no hearing deficits but had recurrent headache. He had chronic back pain and stiffness and no previous fractures.

Skeletal plain radiographs showed generalized thickening of the skull (Fig. 1A) and diaphysis of long bones (Fig. 2A and C). Head magnetic resonance imaging (MRI) showed cranial hyperostosis with significant thickening of all skull bones but no cranial nerve compression and no macrocephaly. Spinal MRI showed dense vertebral bodies, cervical and lumbal foraminal stenosis at several levels and lumbar disc prolaps with spinal canal stenosis at L3-L4. The bone formation marker amino-terminal propeptide (PINP) of type I collagen, was increased $93 \mu \mathrm{g} / \mathrm{l}$ (normal 20-76 $\mu \mathrm{g} / \mathrm{l}$ ). All other laboratory findings including hematology and markers of calcium homeostasis (calcium, phosphate, alkaline phosphatase, parathyroid hormone) were normal.

We performed Sanger sequencing on genomic DNA to look for potential changes in LRP5 (Supplemental Fig. S1). A novel heterozygous LRP5 missense mutation, c.592A > T (p.N198Y), was identified in exon 3 (reference sequence: NM_002335.3) (Supplemental Fig. S1-S2). Based on the mutation's location it was predicted to be an activating mutation leading to increased WNT signaling. The index patient's mother and two sisters, all clinically asymptomatic, were negative for the mutation; the father had deceased and no DNA was available for investigation (Supplemental Fig. S1).

\subsection{Patient II}

This presently 17-year-old female was born to healthy parents preterm at 35 weeks of gestation. Her birth measurements were $46 \mathrm{~cm}(-2.4 \mathrm{SD})$ and $2510 \mathrm{~g}(-2.4 \mathrm{SD})$ and the head circumference was $35.5 \mathrm{~cm}(+0.2 \mathrm{SD})$. She had triangular face, hypertelorism, micrognatia, short neck, flat nasal bridge, large open fontanelles, and two-parted xyphoid process (bifidi xiphoid). Brain ultrasound and MRI were performed due to rapidly increasing head circumference. White matter was decreased and lateral ventricles widened but there were no signs of hydrocephaly and the cause of macrocephaly remained unknown. Laryngobronchoscopy at age 1 year revealed choanal stenosis with layngomalasia and subglottic stenosis. Her ear and nose canals were narrow leading to recurrent ear infections. Abdominal ultrasound showed no apparent abnormalities. She had normal hearing but no stereovision. The motor development was delayed. Treatment-responsive epilepsy was diagnosed at 13 years. Later in life, she had otherwise normal growth (height $+1.0 \mathrm{SD}$, BMI $23.6 \mathrm{~kg} / \mathrm{m}^{2}$ ) and pubertal development. Macrocephaly has persisted at +6.0 SD. Dental problems have necessitated orthodontic treatment for over 10 years. A clinical diagnosis of pycnodysostosis was made in early childhood but later diagnosis of OSCS was considered based on radiographic findings and craniofacial characteristics.

Radiography displayed severe hyperostosis with longitudinal striations and uneven bone mineralization (Fig. 2B and D). Cranial plain radiographs depicted severe macrocephaly with underdeveloped sinuses, small jaw and open fontanels (Fig. 1B). Long bones and phalanges were abnormal in shape. Spinal images showed normal vertebrae, mild scoliosis, and no bone-in-bone features. DXA measurement at 17 years showed increased BMD with Zscores +3.0 for lumbar spine and +2.4 for femoral neck, confirming generalized high bone mass.

Extensive studies were performed in childhood to determine the cause of her skeletal phenotype. Biochemical parameters of calcium homeostasis were normal. Chromosomes, fibroblast lyzosomal enzyme activity, and organic amino acids were normal. A 21 osteopetrosis gene panel at Bristol RGC, UK Genetic Testing Network, found a novel X-chromosomal heterozygous deletion c.655del (p.E219Rfs*63) in AMER1 (APC Membrane Recruiting Protein 1) (reference sequence: NM_152424.3) (Supplemental Fig. S3). The one-base deletion likely leads to premature termination of the gene product. This putative loss of function (LOF) mutation has not been described before but the gene's other previously described mutations are associated with OSCS (OMIM \#: 300373). No parental samples were available for testing but the mutation was determined de novo as the parents and younger brother were healthy.

\section{Discussion}

High bone mass (HBM) is a rare skeletal condition characterized by increased BMD. Excessive bone deposition is usually most prominent in cranial and tubular bones but the clinical characteristics are heterogeneous. The underlying molecular and genetic mechanisms are also diverse and both, malfunctioning osteoclasts and subsequent decrease in bone resorption as well as increased osteoblast function, with consequent excessive bone deposition can lead to similar phenotypes. This study describes two novel mutations in two patients with HBM and portrays how mutated LRP5 and AMER1 and consequent increase in WNT signaling cause excessive bone deposition with differences in phenotypes.

We adopted the candidate gene approach to identify the genetic defect causing HBM in our first index patient. The most commonly mutated gene in HBM is LRP5 and 14 activating mutations have been identified in this gene thus far (Supplemental Fig. S2). The previously identified mutations are all missense, except one small deletion (Supplemental Fig. S2). Furthermore, HBM LRP5 mutations 

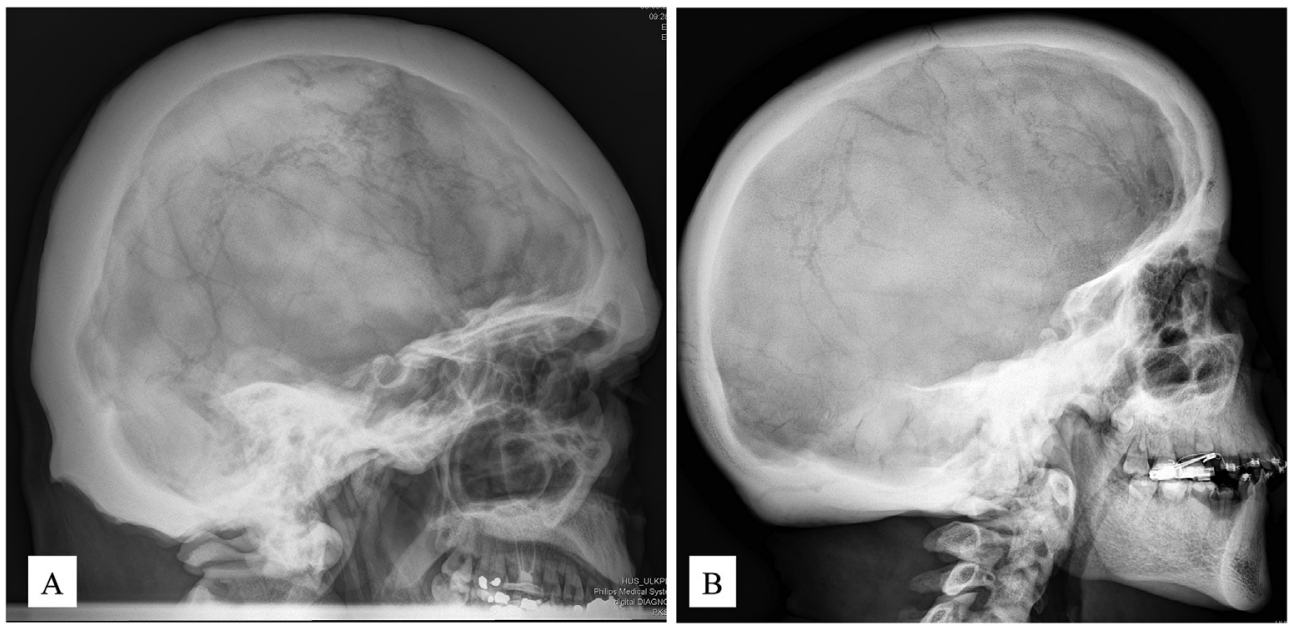

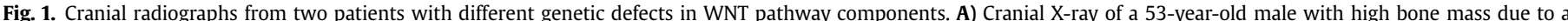

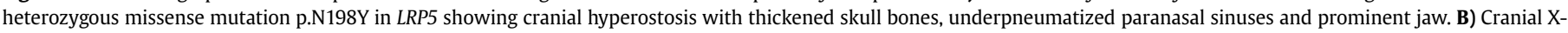

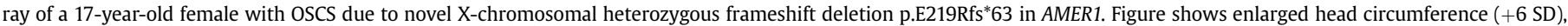
dense cranial bones and prominent jaw.
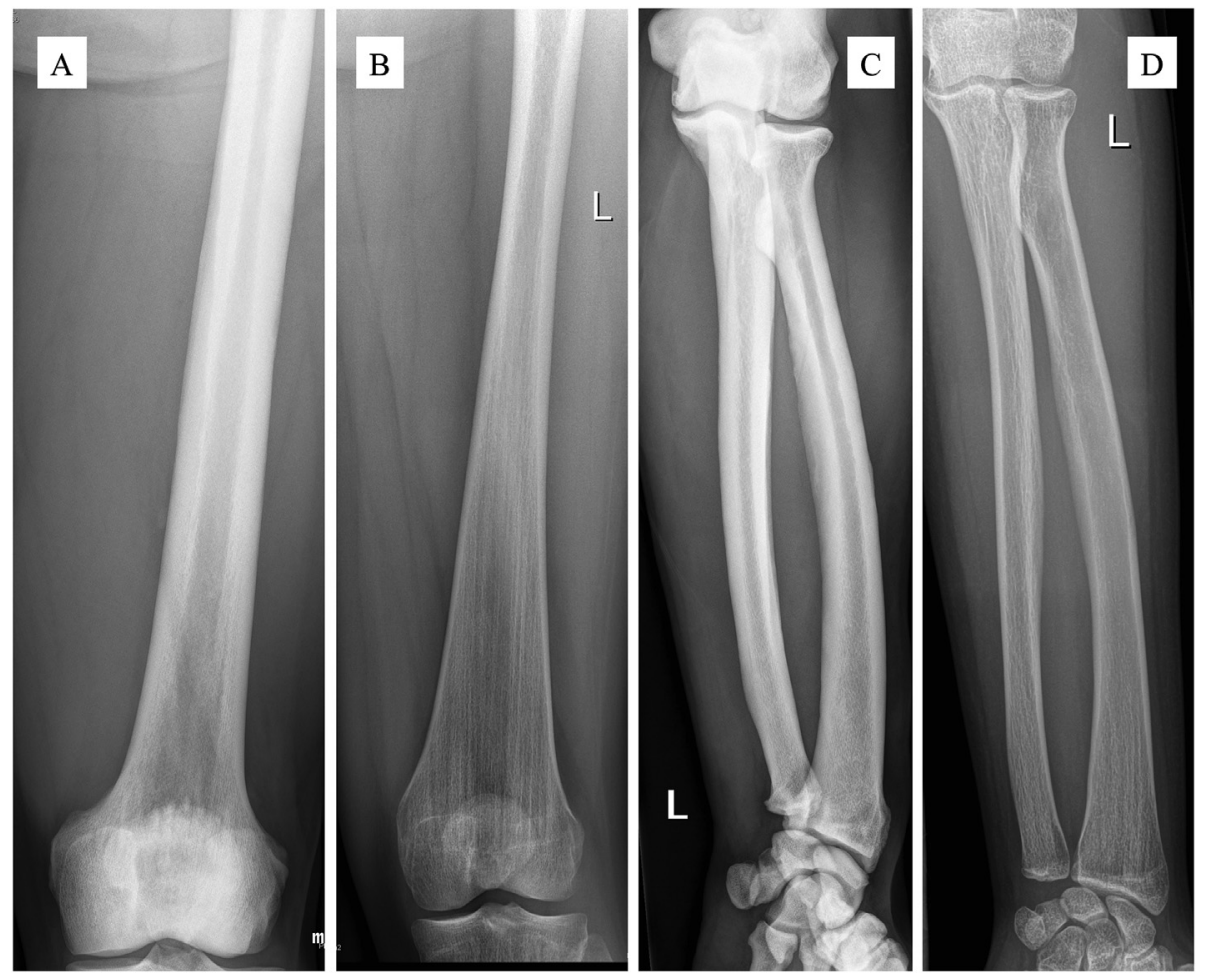

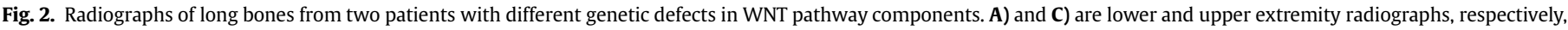

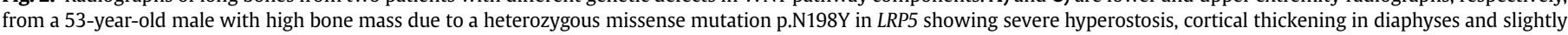

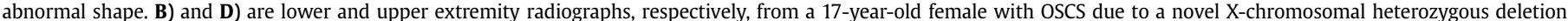
p.E219Rfs*63 in AMER1 showing striated patterning and abnormal shape.

have only been identified in exons $2-4$ corresponding to the $\beta$ propeller 1 in the protein (Gregson et al., 2016; Supplemental Fig. 2). For this reason we sequenced only these exons and identified a novel missense mutation, c.592A $>\mathrm{T}$ (p.N198Y), in exon 3. Another mutation in the same codon (p.N198S) has already been reported as pathogenic (Gregson et al., 2016); this has been defined as one of the most important among the HBM mutations since Asparagine 198 strictly interacts with the Asparagine of the "NXI" motif of the SOST/DKK1 inhibitors (Bourhis et al., 2011). The previously identified mutation converts Asparagine into Serine, two amino acids that belong to the same chemical group and causes a loss of affinity for the inhibitors due to the different amino acid structure (Gregson et al., 2016). Our mutation instead converts Asparagine into Tyrosine. These two amino acids have different chemical-physical characteristics and in this way this mutation may have an even more deleterious impact on the protein. The mutation locates in the $\beta$-propeller 1 , where the Dickkopf WNT Signaling Pathway Inhibitor 1 (DKK1) binds (Ai et al., 2005). DKK1 
encodes an antagonist of the WNT co-receptors LRP5 and LRP6. Sclerostin (encoded by SOST) is also an antagonist for these coreceptors. LOF mutations in SOST lead to upregulation of the $\mathrm{WNT} / \beta$-catenin pathway and bone formation is promoted. The WNT pathway can be also up-regulated by gain of function mutations of LRP5 because they impair the binding of the ligand DKK1 to its co-receptor. In this way the canonical WNT pathway escapes inhibition and BMD increases (Balemans et al., 2008). This mechanism is likely to cause the disease in our index patient. Furthermore, his skeletal phenotype, characterized by hyperostosis not restricted to skull but affecting the whole skeleton, overlaps with the phenotype of the other patients with HBM and supports the presence of a germline gain of function mutation (Gregson et al., 2016). Usually, patients with HBM have torus palatinum but instead our patient had torus mandibularis.

Our second patient is affected by OSCS, which is a rare form of skeletal dysplasia. Mutations in AMER1 were first discovered as the underlying cause in 2009 and since then many other patients and families have been described with novel mutations and varying clinical characteristics (Supplemental Fig. S3) (Jenkins et al., 2009). Our patient's phenotype is in congruence with the common traits in female patients and diagnosis is confirmed by radiographic signs of sclerosis of skull and long bones with longitudinal striations. These striations may be the result of a random $X$ inactivation in the osteoblast lineage cells since they are usually absent in male patients with AMER1 mutations (Ciceri et al., 2013; Jenkins et al., 2009; Perdu et al., 2010). Due to X-linked dominant inheritance, the condition is significantly more severe in males and usually associated with fetal or neonatal lethality. Surviving males exhibit severe multiorgan malformations and hyperostosis (Holman et al., 2011; Jenkins et al., 2009). AMER1 functions intracellularly to suppress WNT signaling by promoting the ubiquitination and degradation of $\beta$-catenin (Tanneberger et al., 2011). Inactivating mutations in AMER1 lead to accumulation of active cytoplasmic $\beta$ catenin and consequently translocation of $\beta$-catenin to the nucleus, increased target gene transcription and excessive bone formation (Major et al., 2007). Although AMER1, also referred to as WTX (Wilms tumor X-linked), is a tumor suppressor gene and somatic mutations lead to Wilms tumor (OMIM \#: 194070), OSCS patients with germline mutations do not seem to be predisposed to cancer (Jenkins et al., 2009). However, there are exceptions: a female patient with OSCS also developed hepatoblastoma (Fujita et al., 2014). For this reason careful follow up to exclude malignancies, such as Wilms tumor, is indicated in patients with OSCS. Concerning our patient, no malignancies or suspicious symptoms have thus far been observed and follow-up will continue.

Differentiating between various HBM disorders can appear complex. Both of our patients went through several examinations or surgeries and biochemical tests before arriving at their final diagnosis. The recent advances in understanding the genetic and molecular mechanisms governing bone health, expansion of available genetic tests and the data on rare variants have increased our understanding and enable early diagnosis, genetic counseling and proper management. Although our study lacks in vitro validations there is good evidence from the literature that the observed novel mutations in LRP5 and AMER1 cause HBM through increased WNT signaling.

In conclusion, we identified a novel missense LRP5 mutation and a novel X-chromosomal heterozygous deletion in AMER1 both causing HBM. Our findings expand the spectrum of WNT pathwayrelated mutations causing HBM. Furthermore, our work elucidates how defects in the same pathway but in two different proteins give rise to parallel phenotypes with different modes of inheritance and careful clinical and radiological evaluation is needed for accurate diagnosis.

\section{Competing interests}

The authors declare that they have no competing interests.

\section{Acknowledgments}

Not applicable.

\section{Appendix A. Supplementary data}

Supplementary data related to this article can be found at http:// dx.doi.org/10.1016/j.ejmg.2017.09.001.

\section{Funding source}

Our study was supported by the Swedish Research Council (2013-2603), the Swedish Childhood Cancer Foundation, the Academy of Finland (277843), the Sigrid Jusélius Foundation, the Folkhälsan Research Foundation, and the Novo Nordisk Foundation (21322).

\section{References}

Ai, M., Holmen, S.L., Van Hul, W., Williams, B.O., Warman, M.L., 2005. Reduced af finity to and inhibition by DKK1 form a common mechanism by which high bone mass-associated missense mutations in LRP5 affect canonical Wnt signaling. Mol. Cell Biol. 25 (12), 4946-4955.

Balemans, W., Devogelaer, J.P., Cleiren, E., Piters, E., Caussin, E., Van Hul, W., 2007. Novel LRP5 missense mutation in a patient with a high bone mass phenotype results in decreased DKK1-mediated inhibition of Wnt signaling. J. Bone Miner Res. Offic. J. Am. Soc. Bone Miner. Res. 22 (5), 708-716.

Balemans, W., Ebeling, M., Patel, N., Van Hul, E., Olson, P., Dioszegi, M., Lacza, C. Wuyts, W., Van den Ende, J., Willems, P., Paes-Alves, A.F., Hill, S., Bueno, M., Ramos, F.J., Tacconi, P., Dikkers, F.G., Stratakis, C., Lindpaintner, K., Vickery, B. Foernzler, D., Van Hul, W., 2001. Increased bone density in sclerosteosis is due to the deficiency of a novel secreted protein (SOST). Hum. Mol. Genet. 10 (5), 537-543.

Balemans, W., Piters, E., Cleiren, E., Ai, M., Van Wesenbeeck, L., Warman, M.L., Van Hul, W., 2008. The binding between sclerostin and LRP5 is altered by DKK1 and by high-bone mass LRP5 mutations. Calcif. tissue Int. 82 (6), 445-453.

Bourhis, E., Wang, W.R., Tam, C., Hwang, J.Y., Zhang, Y.N., Spittler, D., Huang, O.W. Gong, Y., Estevez, A., Zilberleyb, I., Rouge, L., Chiu, C., Wu, Y., Costa, M. Hannoush, R.N., Franke, Y., Cochran, A.G., 2011. Wnt antagonists bind through a short peptide to the first beta-propeller domain of LRP5/6. Structure 19 (10) 1433-1442.

Ciceri, S., Cattaneo, E., Fossati, C., Radice, P., Selicorni, A., Perotti, D., 2013. First evidence of vertical paternal transmission of osteopatia striata with cranial sclerosis. Am. J. Med. Genet. Part A 161 (5), 1173-1176.

Fujita, A., Ochi, N., Fujimaki, H., Muramatsu, H., Takahashi, Y., Natsume, J., Kojima, S. Nakashima, M., Tsurusaki, Y., Saitsu, H., Matsumoto, N., Miyake, N., 2014 A novel WTX mutation in a female patient with osteopathia striata with cranial sclerosis and hepatoblastoma. Am. J. Med. Genet. Part A 164A (4), 998-1002.

Gong, Y., Slee, R.B., Fukai, N., Rawadi, G., Roman-Roman, S., Reginato, A.M., Wang, H., Cundy, T., Glorieux, F.H., Lev, D., Zacharin, M., Oexle, K., Marcelino, J. Suwairi, W., Heeger, S., Sabatakos, G., Apte, S., Adkins, W.N., Allgrove, J., ArslanKirchner, M., Batch, J.A., Beighton, P., Black, G.C., Boles, R.G., Boon, L.M. Borrone, C., Brunner, H.G., Carle, G.F., Dallapiccola, B., De Paepe, A., Floege, B. Halfhide, M.L., Hall, B., Hennekam, R.C., Hirose, T., Jans, A., Juppner, H., Kim, C.A., Keppler-Noreuil, K., Kohlschuetter, A., LaCombe, D., Lambert, M., Lemyre, E. Letteboer, T., Peltonen, L., Ramesar, R.S., Romanengo, M., Somer, H., SteichenGersdorf, E., Steinmann, B., Sullivan, B., Superti-Furga, A., Swoboda, W., van den Boogaard, M.J., Van Hul, W., Vikkula, M., Votruba, M., Zabel, B., Garcia, T. Baron, R., Olsen, B.R., Warman, M.L., Osteoporosis-Pseudoglioma Syndrome Collaborative, G, 2001. LDL receptor-related protein 5 (LRP5) affects bone accrual and eye development. Cell 107 (4), 513-523.

Gregson, C.L., Wheeler, L., Hardcastle, S.A., Appleton, L.H., Addison, K.A. Brugmans, M., Clark, G.R., Ward, K.A., Paggiosi, M., Stone, M., Thomas, J., Agarwal, R., Poole, K.E., McCloskey, E., Fraser, W.D., Williams, E., Bullock, A.N., Davey Smith, G., Brown, M.A., Tobias, J.H., Duncan, E.L., 2016. Mutations in known monogenic high bone mass loci only explain a small proportion of high bone mass cases. J. Bone Miner. Res. Offic. J. Am. Soc. Bone Miner. Res. 31 (3), 640-649.

Holman, S.K., Daniel, P., Jenkins, Z.A., Herron, R.L., Morgan, T., Savarirayan, R., Chow, C.W., Bohring, A., Mosel, A., Lacombe, D., Steiner, B., Schmitt-Mechelke, T. Schroter, B., Raas-Rothschild, A., Miñaur, S.G., Porteous, M., Parker, M. Quarrell, O., Tapon, D., Cormier-Daire, V., Mansour, S., Nash, R., Bindoff, L.A., Fiskerstrand, T., Robertson, S.P., 2011. The male phenotype in osteopathia striata congenita with cranial sclerosis. Am. J. Med. Genet. Part A 155 (10), 2397-2408. 
Jenkins, Z.A., van Kogelenberg, M., Morgan, T., Jeffs, A., Fukuzawa, R., Pearl, E., Thaller, C., Hing, A.V., Porteous, M.E., Garcia-Minaur, S., Bohring, A., Lacombe, D. Stewart, F., Fiskerstrand, T., Bindoff, L., Berland, S., Ades, L.C., Tchan, M., David, A., Wilson, L.C., Hennekam, R.C., Donnai, D., Mansour, S., CormierDaire, V., Robertson, S.P., 2009. Germline mutations in WTX cause a sclerosing skeletal dysplasia but do not predispose to tumorigenesis. Nat. Genet. 41 (1) 95-100.

Laine, C.M., Chung, B.D., Susic, M., Prescott, T., Semler, O., Fiskerstrand, T. D'Eufemia, P., Castori, M., Pekkinen, M., Sochett, E., Cole, W.G., Netzer, C. Makitie, O., 2011. Novel mutations affecting LRP5 splicing in patients with osteoporosis-pseudoglioma syndrome (OPPG). Eur. J. Hum. Genet. 19 (8), 875-881.

Laine, C.M., Joeng K.S. Campeau, P.M., Kiviranta, R, Tarkkonen, K., Grover, M. Lu, J.T., Pekkinen, M., Wessman, M., Heino, T.J., Nieminen-Pihala, V., Aronen, M., Laine, T., Kroger, H., Cole, W.G., Lehesjoki, A.E., Nevarez, L., Krakow, D. Curry, C.J., Cohn, D.H., Gibbs, R.A., Lee, B.H., Makitie, O., 2013. WNT1 mutations in early-onset osteoporosis and osteogenesis imperfecta. N. Engl. J. Med. 368 (19), 1809-1816.

Loots, G.G., Kneissel, M., Keller, H., Baptist, M., Chang, J., Collette, N.M. Ovcharenko, D., Plajzer-Frick, I., Rubin, E.M., 2005. Genomic deletion of a longrange bone enhancer misregulates sclerostin in Van Buchem disease. Genome
Res. 15 (7), 928-935.

Major, M.B., Camp, N.D., Berndt, J.D., Yi, X., Goldenberg, S.J. Hubbert, C. Biechele, T.L., Gingras, A.C., Zheng, N., Maccoss, M.J., Angers, S., Moon, R.T., 2007. Wilms tumor suppressor WTX negatively regulates WNT/beta-catenin signaling. Science 316 (5827), 1043-1046.

Makitie, R.E., Haanpaa, M., Valta, H., Pekkinen, M., Laine, C.M., Lehesjoki, A.E. Schalin-Jantti, C., Makitie, O., 2016. Skeletal characteristics of WNT1 osteoporosis in children and young adults. J. Bone Miner. Res. Offic. J. Am. Soc. Bone Miner. Res. 31 (9), 1734-1742.

Perdu, B., de Freitas, F., Frints, S.G., Schouten, M., Schrander-Stumpel, C., Barbosa, M., Pinto-Basto, J., Reis-Lima, M., de Vernejoul, M.C., Becker, K., Freckmann, M.L., Keymolen, K., Haan, E., Savarirayan, R., Koenig, R., Zabel, B., Vanhoenacker, F.M., Van Hul, W. 2010. Osteopathia striata with cranial sclerosis owing to WTX gene defect. J. Bone Miner. Res. Offic. J. Am. Soc. Bone Miner. Res. 25 (1), 82-90.

Saarinen, A., Mayranpaa, M.K., Lehesjoki, A.E., Makitie, O., 2010. Low-density lipoprotein receptor-related protein 5 (LRP5) variation in fracture prone children. Bone 46 (4), 940-945.

Tanneberger, K., Pfister, A.S., Kriz, V., Bryja, V., Schambony, A., Behrens, J., 2011. Structural and functional characterization of the Wnt inhibitor APC membrane recruitment 1 (Amer1). J. Biol. Chem. 286 (22), 19204-19214. 